\title{
En torno a la asamblea general de las sociedades cooperativas
}

\author{
Fernando Sacristán Bergia \\ Profesor Titular Derecho Mercantil URJC \\ Abogado
}

Sumario: I. Introducción. II. La asamblea general. A. Caracterización. B. Sobre el marco de competencias de la asamblea. C. Las clases de asambleas. III. Sobre la convocatoria de la asamblea general. A. Competencia. Forma y plazo. B. Contenido. C. La posición del socio. IV. El funcionamiento de la asamblea general. A. La mesa de la asamblea. La presidencia. B. El quórum y lista de asistentes. C. Sobre el desarrollo de la reunión. El derecho de voto. D. El acta de la reunión. V. Impugnación de acuerdos sociales.

Resumen: En este trabajo el autor ofrece una visión práctica del funcionamiento de la Asamblea General de las Cooperativas. Se incluye una exposición de las principales características de la Asamblea General y su encuadramiento en la estructura orgánica de la cooperativa, con referencia al ámbito de sus competencias. A lo largo del trabajo se tratan los principales aspectos formales del funcionamiento de la asamblea, la posición del socio, así como el desarrollo de la reunión, y la votación de los puntos previstos en el orden del día.

Palabras clave: Asamblea General, convocatoria, orden del día, posición de socio, acta, impugnación.

Abstract: This paper provides a practical vision of how the General Assembly of cooperatives works. It includes an explanation of the main characteristics of the General Assembly, how it fits into the organisational structure of the cooperative and its powers. Throughout the paper, the author discusses the main formal aspects of how the assembly functions, the role of members and how the meetings and voting on items on the agenda are held.

Key words: General Assembly, convene, agenda, the role of members, minutes, contest. 


\section{Introducción}

El modelo de estructura orgánica de las cooperativas previsto la Ley 27/1999 de 26 de Julio, distingue entre los órganos necesarios, que son el órgano de administración, la Asamblea General, y los Interventores. Y los órganos facultativos, como el Comité de Recursos y, aquellos otros que se designen en los Estatutos siempre que no interfieran las competencias que aparezcan atribuidas en la Ley a otro órganos. En el marco de las Leyes de las distintas Comunidades Autónomas se sigue este esquema, pero hay que advertir que podemos encontrar excepciones y novedades, así por ej., entre otras, la Ley Valenciana (Ley 8/2003 de 24 de marzo), no recoge a los interventores entre los órganos necesarios, aunque estatutariamente se pueden establecer comités de control de la gestión.

La asamblea general se presenta como el órgano de decisión, se dice que la asamblea es el órgano soberano de la Cooperativa. El órgano de administración tradicional es el Consejo Rector, que se encarga de la representación y alta gestión de las cooperativas, aunque en las cooperativas de menos de 10 socios, es posible que el órgano de administración se configure por medio de un administrador único. Los Interventores ocupan un papel fiscalizador de la actuación del órgano de administración, su firma dando el visto bueno a la elaboración y contenido de las cuentas anuales, se presenta como un paso necesario y previo a la convocatoria de la asamblea ordinaria, y ello sin perjuicio de la necesaria intervención de Auditores cuando por las características de la cooperativa, o por acuerdo de la Asamblea sea necesario su nombramiento. En esta trabajo pretendemos realizar una aproximación con sentido práctico al funcionamiento de la asamblea general, para lo que tomaremos como referencia el texto de la legislación estatal de Cooperativas (Ley 27/1999 de 26 de Julio, en adelante LCoop).

\section{La asamblea general}

\section{A. Caracterización}

Podemos definir la asamblea general como la reunión de socios previamente convocada al efecto, que decide por mayoría los asuntos propios de su competencia incluidos en el orden del día, y cuyos acuerdos son vinculantes para todos los socios, incluso los no asistentes. A través de los acuerdos de la Asamblea se configura la voluntad social, que en el marco establecido en la Ley y los Estatutos vincula al órgano de administración. 
En consecuencia, podemos señalar como elementos definidores de la Asamblea General son: que se trata de una reunión de socios, que actúa previa convocatoria, y que adopta acuerdos vinculantes en las materias de su competencia por las mayorías previstas en la Ley y en los estatutos. La asamblea como todo órgano colegiado actúa previa convocatoria, y la convocatoria debe adecuarse a todos los requisitos legales de forma y contenido para que sea válida la Asamblea. El contenido de la convocatoria tiene una enorme importancia porque limita los acuerdos que pueden aprobarse en la asamblea que, salvo las excepciones previstas en la Ley, sólo podrán referirse a los puntos previstos en el orden del día. En los siguientes apartados nos proponemos desarrollar el estudio de estos elementos.

\section{B. Sobre el marco de competencias de la asamblea}

El marco de las competencias de la asamblea aparece delimitado expresamente en el artículo 21 LCoop., que se refiere a cuales son las materias cuya competencia está encomendada en exclusiva a la Asamblea:

a) Censura de la gestión social, aprobación de las cuentas anuales, informe de gestión, aplicación de excedentes o imputación de pérdidas.

b) Nombramiento y revocación de los miembros del consejo rector, de los interventores, de los auditores de cuentas, de los liquidadores y, en su caso del comité de recursos, así como de la cuantía de las retribuciones de los consejeros y liquidadores.

c) Modificación de los Estatutos, y aprobación o modificación en su caso, del Reglamento del Régimen Interno de la cooperativa.

d) Aprobación de nuevas aportaciones obligatorias, admisión de aportaciones voluntarias, actualización del valor de las aportaciones al capital social, fijación de las nuevas aportaciones de los nuevos socios, establecimiento de cuotas de ingreso o periódicas, así como el tipo de interés a abonar por las aportaciones al capital social.

e) Emisión de obligaciones, títulos participativos, participaciones especiales u otras formas de financiación mediante la emisión de valores negociales.

f) Fusión, escisión, transformación, y disolución de la sociedad.

g) Toda decisión que suponga una modificación sustancial, según los estatutos, de la estructura económica, social, organizativa o funcional de la cooperativa. 
h) Constitución de cooperativas de segundo grado y de grupos cooperativos o incorporación de estos si ya están constituidos, participación en otras formas de colaboración económica previstas en la Ley, adhesión a entidades de carácter representativo así como la separación de las mismas.

i) El ejercicio de una acción social de responsabilidad contra los miembros del consejo rector, los auditores de cuentas y los liquidadores.

j) Los derivados de una norma legal o estatutaria.

La anterior enumeración de las competencias de la asamblea prevista en la LCoop., no es completa, con frecuencia encontramos otras materias que son reservadas a la asamblea en otros preceptos de la Ley, así podemos referirnos entre otras a la ratificación de la expulsión de un socio (art. 18.5 LCoop), la competencia para aprobar que la cooperativa pueda obligarse con algún consejero, interventor o uno de sus parientes hasta el segundo grado de consanguinidad (art. 42. LCoop), y la aprobación del balance final de liquidación (art. 74 LCoop). La competencia en las materias atribuidas por Ley a la Asamblea son indelegables.

La asamblea general también puede impartir instrucciones al órgano de administración, siempre que no interfiera en las materias que por ley les corresponden en exclusiva a los administradores (así lo establece expresamente por ej. el art.29.4 de la Ley Madrileña de Cooperativas, y a falta de previsión legal especial, puede introducirse una norma semejante en los estatutos, aunque en ausencia de previsión legal o estatutaria, tampoco se podría discutir la competencia de la asamblea para impartir instrucciones que afectan a la política de actuación de la sociedad porque es el órgano soberano). Lo anterior significa que la asamblea como órgano soberano puede dar instrucciones en todo aquello que afecte a la política general de actuación de la cooperativa, y que los administradores deben ajustarse a las instrucciones recibidas. También es posible que a efectos internos, los socios adopten el acuerdo de limitar cuantitativamente la competencia de los administradores requiriendo su autorización para realizar operaciones con una determinada trascendencia económica, tales limitaciones, igual que las instrucciones vinculan a los administradores con la sociedad, pero no limitan sus competencias frente a terceros, de manera que si incumplieran sus instrucciones, la operación frente a terceros de buena fe sería válida, pero la sociedad podría exigirles responsabilidades por haber incumplido los acuerdos de la asamblea.

En relación con la competencia exclusiva de la asamblea para tomar decisiones que supongan una modificación sustancial de la estructura económica de la cooperativa, algunas leyes autonómicas precisan que 
debe entenderse por modificación sustancial, y establecen la competencia de la asamblea para la «transmisión del conjunto de la empresa o patrimonio de la cooperativa, integrado por el activo o pasivo; o de todo el activo; o de elementos del inmovilizado que constituyan más del $20 \%$ del mismo, sin perjuicio de la competencia del consejo rector para la ejecución de dicho acuerdo.

En cuanto a los límites a la competencia de la asamblea señalamos aquellas materias que la Ley haya atribuido en exclusiva a otros órganos, como ocurre con la representación de la sociedad, que corresponde en exclusiva al órgano de administración, respecto de la gestión de la sociedad, que también corresponde al órgano de administración, debe tenerse en cuenta lo ya señalado sobre la posibilidad de impartir instrucciones a los administradores, posibilidad coherente con el carácter soberano de la Asamblea. En cuanto a los límites al contenido de los acuerdos de la asamblea en aquellas materias en las que sea competente, los acuerdos siempre deben ajustarse a lo dispuesto en la Ley y en los estatutos, y respetar los intereses sociales.

\section{Las clases de asambleas}

La siguiente cuestión que debemos plantearnos es la de las distintas clases de asambleas generales previstas en la Ley, distinguiéndose entre asambleas ordinarias, y extraordinarias, además, en la legislación de cooperativas hay una clase especial de asamblea que es la llamada Asamblea de Delegados.

Siguiendo el criterio tradicional de clasificación, diferenciamos entre asambleas ordinarias y extraordinarias. El criterio para distinguir unas de otras lo tenemos en su carácter periódico, de manera que podemos definir como asambleas ordinarias aquellas cuya celebración está prevista en la Ley o en los estatutos, y son extraordinarias las que no están previamente previstas. La LCoop aborda esta distinción en los art.22 y 23 de forma similar a como se hace en la legislación autonómica, señalando que la asamblea ordinaria debe celebrarse dentro de los seis meses siguientes a la fecha de cierre del ejercicio económico, para censurar la gestión social aprobar las cuentas anuales y resolver sobre la aplicación de resultados. Hay que tener en cuenta que también es posible incluir en el orden del día de una asamblea ordinaria cualquier otro punto que los administradores consideren oportuno.

En consecuencia, lo característico de la Asamblea ordinaria es su periodicidad y su carácter obligatorio. La convocatoria dentro del plazo previsto es una obligación de los administradores, para el caso en que 
trascurra el plazo sin haberse convocado, los interventores tiene la obligación de instar a los administradores la convocatoria y si estos no convocan en los quince días siguientes al requerimiento deben instarla del juez competente que la convocará. Atendiendo al carácter necesario de la asamblea ordinaria, si los administradores o los interventores no cumplieran sus obligaciones en orden a la convocatoria, cualquier socio está legitimado para solicitar la convocatoria al Juez competente, que será el Juez de lo Mercantil del domicilio de la cooperativa (la posición de los interventores respecto de la asamblea encuentra un tratamiento diferente en alguna de las Leyes autonómicas).

La solicitud judicial de convocatoria dará lugar al correspondiente expediente de jurisdicción voluntaria. El presupuesto necesario para la convocatoria judicial es la constatación de la falta de convocatoria en plazo por los administradores. Para que el Juez acuerde la convocatoria es necesaria la previa audiencia de los administradores. En estos casos, el Juez designará quien debe presidir la Asamblea. En cuanto a la forma de la convocatoria judicial, además de la resolución judicial acordándolo es necesario que se respeten los medios de publicidad previstos en la Ley y en los estatutos. Hay que tener en cuenta el carácter subsidiario de la convocatoria judicial, de manera que una vez iniciado el expediente de jurisdicción voluntaria si los administradores convocasen la asamblea, podría pensarse que la convocatoria produciría todos los efectos, y el procedimiento judicial quedaría sin efecto al no tener ya sentido.

Cualquier otra asamblea no prevista en la Ley o en los Estatutos tendrá el carácter de extraordinaria. Los administradores podrán convocar la asamblea siempre que lo consideren oportuno, y deben convocarla, cuando se lo soliciten fehacientemente socios que representen el 20\% del capital social, y si lo establecen expresamente los estatutos también deben convocarla cuando lo soliciten los interventores. Debe tenerse en cuenta que el porcentaje de socios legitimado para solicitar la convocatoria de la asamblea extraordinaria varia de unas Leyes autonómicas a otras.

La LCoop establece que el requerimiento de convocatoria se debe hacer fehacientemente, entendemos que para que sea fehaciente el requerimiento debe ser notarial, otra cosa hubiese sido si la LCoop se hubiera referido simplemente a que había que dejar constancia de dicha solicitud, en cuyo caso hubiesen sido válidas otras formas de requerimiento de convocatoria como por medio de burofax con certificación de texto. En el ámbito de la legislación autonómica con frecuencia no se indica nada sobre la forma del requerimiento, lo que podría llevar a pensar que es una opción legislativa pretendiendo dar libertad de forma, creo que no ha sido esa la intención, parece que se trata de una laguna que debe subsanarse por medio de la aplicación supletoria de la LCoop. 
El requerimiento de convocatoria debe ser atendido en el plazo de un mes, en este plazo los administradores deben convocar la Asamblea solicitada. Para que el requerimiento de convocatoria surta efectos y surja la obligación de convocatoria es necesario que además de cumplir con los requisitos de forma antes indicados, los socios representen el porcentaje señalado en la Ley, y que en el propio requerimiento se indique el orden del día a tratar en la Asamblea solicitada. Los administradores deben incluir en el orden del día los puntos propuestos y también podrán incluir otros que consideren oportunos.

En el marco de las sociedades cooperativas encontramos, además, un supuesto especial de asamblea que es la Asamblea de Delegados (artículo 30 de la LCoop). La Asamblea de delegados es una especialidad prevista para facilitar y hacer viable la celebración de las asambleas en aquellas cooperativas con un elevado número de socios, o cuando concurran otras circunstancias que hagan difícil la asistencia de los socios (Ej. que los socios vivan alejados del domicilio social en el art.39.1 de la Ley Valenciana). Este sistema permite que a la asamblea general asistan los delegados elegidos por los socios en las juntas o asambleas preparatorias. Para que se puedan celebrar Asambleas de Delegados es necesario que esté previsto en los estatutos, estableciéndose los criterios para la adscripción de los socios a las juntas preparatorias, las normas para la elección de los delegados y el número máximo de votos que les correspondan a cada uno. La convocatoria de la asamblea general y de las juntas preparatorias es única y con los mismos puntos del orden del día. Las juntas preparatorias se celebraran primero, y sirven para que se elija a los representantes que asistirán a la asamblea, y aunque es posible que el nombramiento de delegados se efectúe con un mandato de hasta tres años, la celebración de la junta preparatoria también es necesaria porque en este caso los estatutos deben establecer la celebración de reuniones informativas previas y posteriores a la Asamblea. El mandato que reciban los delegados podrá ser facultativo o con instrucciones de voto de acuerdo con lo acordado en la Junta preparatoria, pero en todo caso los delegados debe actuar de buena fe con la diligencia de un representante.

\section{Sobre la convocatoria de la Asamblea General}

\section{A. Competencia. Forma y plazo}

En cuanto a la competencia para convocar la Asamblea General, tal y como hemos estudiado en el apartado anterior, corresponde al ór- 
gano de administración, y supletoriamente para los supuestos de inactividad de los administradores en los términos antes señalados, corresponde al Juez competente y, cuando lo establezca la Ley aplicable también podrán convocar la asamblea los interventores, en ausencia de convocatoria por los administradores.

La forma de la convocatoria de la asamblea general de las Cooperativas está prevista en la LCoop (art. 24), estableciendo que la convocatoria debe realizarse por medio de un anuncio en el domicilio social y en cada uno de los centros de trabajo de la cooperativa, sin perjuicio de lo que los Estatutos pueden establecer que se realice a través de un medio de convocatoria individual y por escrito. Cuando la cooperativa tenga más de 500 socios la publicación debe realizarse también por medio de un determinado diario de gran difusión en el territorio donde la cooperativa desarrolle su trabajo.

En consecuencia, junto al régimen previsto en la Ley, los estatutos pueden establecer normas especiales de forma, y exigir que además de los anuncios en el domicilio y centros de trabajo, la convocatoria se comunique individualmente a los socios por cualquier procedimiento de comunicación individual y escrita, que asegure la recepción del anuncio en el domicilio designado al efecto por los socios, o en el que conste en el libro registro. En cuanto al sistema de comunicación individual, lo habitual en los estatutos es que se establezca la comunicación por medio de carta certificada con acuse de recibo. Las Leyes autonómicas más recientes incluyen la posibilidad de realizar la convocatoria a través de medios informáticos para la convocatoria individual, o mediante cualquier sistema previsto en los estatutos que asegure la recepción de la misma. En aquellas supuestos en los que la Ley autonómica aplicable no establezca expresamente esta posibilidad entendemos que resulta posible la comunicación al socio por medio de correo electrónico cuando los estatutos lo establezcan expresamente, pero a falta de previsión estatutaria la convocatoria individual debe hacerse por carta.

En el ámbito de las distintas Leyes autonómicas encontramos matices y novedades sobre la forma de la convocatoria, que en caso por caso deberán tenerse en cuenta.

En cuanto al plazo previsto para la convocatoria en la LCoop, ésta debe publicarse en la forma prevista con una antelación de 15 días como mínimo a dos meses como máximo. Hay que tener en cuenta que para el cómputo del plazo no se incluyen el día de la publicación o remisión de la comunicación, y tampoco el día de la reunión. Estatutariamente se puede establecer un plazo distinto, siempre que no sea inferior al plazo de 15 días o superior al de dos meses. Es destacable que en el marco de las distintas Leyes Autonómicas pueden variar los plazos de convocatoria. 
Hay una excepción a la exigencia de convocatoria previa de la asamblea, la llamada Asamblea General Universal. La Ley establece que es válida la constitución de la Asamblea cuando estén presentes o representados todos los socios de la cooperativa y acepten por unanimidad, constituirse en Asamblea General Universal aprobando todos ellos el orden del día (art. 23.5 LCoop). Son pues, dos los presupuestos necesarios para que se pueda celebrar la asamblea sin convocatoria: que asistan todos los socios personalmente o por medio de representante, y que exista unanimidad sobre el orden del día. Para que la asamblea sea válida bastará que la presencia de todos los socios se de al comienzo de la reunión y exista acuerdo sobre la celebración de la asamblea y el orden del día, y en este sentido la Ley exige que todos los socios firmen un acta en el que se recoja el acuerdo de celebrar la asamblea y el orden del día, dicha acta puede coincidir con el acta de la asamblea, o ser un anexo en aquellos casos en los que la aprobación del acta se demore tal y como permite el art. 29.2 LCoop.

\section{B. Contenido}

En relación con el contenido de la convocatoria, la LCoop establece en el art. 24.2 que como mínimo deben incluirse los datos identificativos de la cooperativa, la identidad del órgano convocante, la fecha, hora y el lugar de reunión, si es en primera o segunda convocatoria, entre las cuales podrá transcurrir media hora, así como también se tienen que incluir los asuntos comprendidos en el orden del día, y demás anuncios legales según los asuntos a tratar, en particular la información sobre la puesta a disposición de los socios de la documentación relacionada con los asuntos a tratar en el orden del día, como ocurriría si se tratase la aprobación de las cuentas anuales por ser necesaria la puesta a disposición de un ejemplar de las mismas en la convocatoria, o en el caso de la modificación de estatutos, el texto de la propuesta de modificación y el informe justificativo de la misma. En la convocatoria también se debe incluir una referencia al derecho del socio a solicitar el envío de dichos documentos cuando así lo establezca la Ley o los estatutos.

En cuanto al orden del día de la convocatoria de las asambleas ordinarias se tiene que incluir necesariamente los puntos previstos en la Ley, así como cualquier otro que los administradores estimen de interés. Los estatutos o la Ley pueden predeterminar la existencia necesaria de un punto concreto en el orden del día, como ocurre, entre otras, con la Ley Valenciana, o la Madrileña que exige que en el orden del día 
se incluya un punto que permita a los socios hacer sugerencias y preguntas al órgano de administración.

En las Asambleas extraordinarias el orden del día lo constituirán las propuestas que a iniciativa de los administradores o de los socios justifiquen su convocatoria. Además, una vez hecha la convocatoria, desde su publicación y hasta los ocho días posteriores a la convocatoria (plazo que varía de unas Leyes autonómicas a otras), los socios que representen el $10 \%$ del capital o los interventores pueden solicitar la inclusión de otros puntos en el orden del día. No se dice en la Ley como deben los socios solicitar la ampliación del orden del día, es aconsejable que se haga por escrito a través de un medio que deje constancia porque el socio debe estar en disposición de acreditar que presentó la solicitud en plazo. El órgano de administración después de verificar que la solicitud cumple los requisitos de representatividad y plazo, debe ampliar el contenido de la convocatoria y comunicárselo a los socios con una antelación de cuatro días a la celebración de la junta (plazo que una vez más puede ser distinto en la legislación autonómica, ej es de 7 días en la Ley Valenciana, y por los mismos medios de publicidad previstos para la convocatoria.

La redacción de los puntos del orden del día debe estar presidida por criterios de claridad, y concreción, de manera que con una simple lectura de la convocatoria los socios conozcan cual va a ser el contenido de la asamblea y puedan valorar su interés por los temas a tratar. La concreción y claridad exigen la determinación del contenido de la convocatoria de manera que para una modificación de estatutos, no seria suficiente con incluir como punto en el orden del día «La modificación de los estatutos de la sociedad», sino que es necesario hacer una referencia a la materia o a los artículos que se van a modificar, incluso atendiendo a la trascendencia de las modificaciones propuestas, también puede hacerse una alusión al sentido de la modificación propuesta.

El contenido del orden del día limita los asuntos que se pueden debatir y aprobar en la reunión, excepcionalmente, la Ley permite que sin estar incluido en el orden del día, la asamblea apruebe el ejercicio de una acción social de responsabilidad contra los administradores y su revocación, la censura de las cuentas por miembros de la cooperativa o por persona externa, o el prorrogar la sesión de la asamblea así como cualquier otro previsto en la Ley.

\section{La posición de socio}

Una vez que el socio conoce la convocatoria de la Asamblea, adquieren relevancia sus derechos de información, asistencia y represen- 
tación, se trata de derechos mínimos de todo socio de cuyo incumplimiento por parte de la cooperativa puede derivarse la impugnación de la Asamblea. El socio a la vista del contenido de la convocatoria, decide cual va a ser su posición ante la asamblea, entrando en juego la posibilidad de ejercitar su derecho de información, o de decidir sobre su asistencia personal o a través de representante.

El derecho de información del socio tiene un papel esencial para la conformación de la voluntad del socio que posteriormente se expresará a través del sentido de su voto, es un derecho fundamental que tiene diversas manifestaciones en relación con la convocatoria de la asamblea. En primer lugar, el socio podrá examinar en el domicilio de la cooperativa o en sus sucursales la documentación puesta a disposición, o en su caso, en vez de asistir personalmente podrá solicitar el envío de dicha documentación a su domicilio. Pero además de este derecho a examinar la documentación relacionada con la asamblea convocada, el socio puede solicitar aclaraciones sobre los puntos del orden del día, dichas aclaraciones se solicitaran a iniciativa del socio con carácter previo a la asamblea en escrito dirigido al órgano de administración, o durante la propia asamblea. No aparece expresamente previsto en la Ley cuando y como deba contestársele al socio las aclaraciones solicitadas sobre los puntos del orden del día, creemos que la respuesta estará en función del momento en que este solicite la información, si la solicita por escrito con tiempo suficiente antes de la asamblea, se le debe contestar por escrito antes de la celebración de la misma, y si lo hiciera verbalmente durante la celebración de la asamblea, se le debe contestar durante la propia reunión, salvo que en ese momento resulte imposible, pudiendo entonces posponerse la información a un plazo razonable después de la asamblea (no obstante alguna de las leyes autonómicas más recientes si establecen normas sobre este punto).

Una especialidad de las cooperativas por la que se refuerza la posición del socio en torno a su derecho de información, es que su ejercicio no está solo limitado a las convocatorias de asambleas y al contenido del orden del día, sino que cada socio puede en cualquier momento solicitar información o aclaraciones sobre la marcha de la cooperativa, y el órgano de administración tiene que responder en el plazo de 30 días (LCoop art. 16.2.f., plazo que varía de unas Leyes autonómicas a otras).

El derecho a la información del socio tiene como límite que la información solicitada ponga en grave peligro los intereses de la cooperativa o resulte perjudicial para los intereses sociales, o a que la petición constituya obstrucción reiterada o abuso manifiesto por parte de los solicitantes, o que deba mantenerse reserva sobre dichos datos en 
cumplimiento de lo dispuesto en una Ley. Estas formulas para establecer los límites al derecho de información se repiten en las distintas leyes autonómicas de cooperativas, y aunque podrían parecer un cajón de sastre en el que por su indeterminación se escude el órgano de administración para no dar la información solicitada, lo cierto es que su aplicación sólo puede alegarse cuando esté justificado y exista prueba de la situación de conflicto con los intereses de la sociedad, porque en caso contrario podría prosperar la impugnación de la asamblea por haberse incumplido el derecho de información, atendiendo a su carácter inderogable y esencial. Esta indeterminación se modera porque se establece la obligación de los administradores de contestar cuando quien solicita la información esté apoyado por más de la mitad de los votos sociales presentes (art. 16.4 LCoop), o cuando la propia asamblea acuerde dar la información como consecuencia del resultado de una votación secreta (art. 26.2.c Ley Valenciana).

Los socios pueden asistir personalmente o también pueden hacerlo por medio de su representante, que puede ser otro socio quien no podrá representar a más de dos (excepto en la Ley Catalana que limita la representación a uno en el art. 35.1). La representación también puede conferirse a un familiar cuando lo autoricen los estatutos, en el marco de la LCoop para que esto sea posible los estatutos tienen que establecer cual deba ser el grado de parentesco. Las Leyes autonómicas más recientes admiten expresamente la representación por medio del cónyuge, pareja de hecho, ascendiente o descendiente, incluso se establece que en este supuesto no es necesario que la presidencia de la asamblea admita la representación cuando el familiar lleve su representación por escrito y acredite el grado de parentesco de acuerdo con la normativa específica.

En el caso de socios personas jurídicas la representación la tienen sus representantes legales, igual que ocurre con las personas físicas sometidas a representación legal. En cualquier caso, la representación debe conferirse por escrito y con carácter especial para cada Asamblea, y en lista de asistentes debe figurar si se asiste por medio de representante y la identidad del mismo.

Además de los socios, es posible que puedan asistir a la Asamblea cualesquiera otras personas que autoricen los estatutos o que a propuesta del presidente autorice la Asamblea. Es frecuente que se permita estatutariamente la asistencia a las reuniones de la asamblea de los técnicos que asesoran en las distintas ramas a la cooperativa, o de los directores o incluso de algún empleado, se trata de una autorización que puede resultar práctica porque atendiendo a la complejidad del orden del día, a lo largo de la celebración de la reunión pudieran necesitar su asesoramiento. 
Para terminar con el análisis de la posición del socio ante la convocatoria de una asamblea, es conveniente tratar el derecho del socio a solicitar la presencia de notario. Los administradores pueden requerir la presencia de notario cuando lo estimen conveniente, y estarán obligados a hacerlo cuando se lo soliciten los socios conforme a lo dispuesto en la Ley. El derecho del socio a solicitar la presencia de notario está sometido al cumplimiento de dos requisitos, que se trate de socios que representen el $10 \%$ de los socios y que se solicite con 7 días de antelación a la asamblea (destacamos que porcentaje y plazo varia de unas normas autonómicas a otras, parece que se trata de un derecho lo suficientemente importante como para que no estén justificadas las diferencias de tratamiento, y estimamos que se debería armonizar su tratamiento en el marco de las distintas leyes, para lo que nos parece adecuado el porcentaje del $5 \%$, que es un porcentaje suficientemente representativo, y cualquier porcentaje superior es difícil de alcanzar y puede hacer de este derecho una mera ilusión.

En cuanto a la forma en la que debe solicitarse la presencia de notario, nada se dice en la Ley, pero como se trata de una solicitud sometida a plazo, parece aconsejable que se utilicen medios que dejen constancia de la fecha y contenido de la solicitud. Para que la solicitud hecha en plazo produzca el efecto de la necesaria intervención notarial, también es necesario que se cumpla con los porcentajes previstos en la Ley. La sociedad corre con los honorarios notariales. En este supuesto el acta notarial será el de la asamblea. La importancia de la presencia de notario se justifica en todos aquellos casos en los que por la trascendencia o por la polémica que puede suscitar el orden del día, queramos que quede constancia del contenido de la reunión, y en particular, de las manifestaciones o hechos que nos preocupan. Cuando se solicita la presencia de notario de acuerdo con lo dispuesto en la Ley, los acuerdos que se adopten en la asamblea sólo serán eficaces si constan en acta notarial.

\section{El funcionamiento de la asamblea general}

\section{A. La mesa de la asamblea. La presidencia.}

Al inicio de la reunión debe constituirse la Mesa de la Presidencia de la Asamblea, que estará formada por el presidente, y el secretario del Consejo Rector, o por quienes designen los estatutos. Cuando éstos no estén presentes, o el órgano de administración no sea un consejo y no aparezca determinado en los estatutos quien debe participar en la mesa, o exista un conflicto de intereses entre los consejeros y los 
puntos del orden del día, la asamblea designará quienes deben ocupar la presidencia. Además del presidente y secretario en la mesa pueden participar las personas que establezcan los estatutos o que autorice la propia asamblea al comienzo de la sesión.

Constituida la mesa y confeccionada la lista de asistentes comienza la reunión siempre que exista quórum suficiente. El presidente declara iniciada la sesión, el papel del presidente es de primer orden, a el le corresponde dirigir la reunión, así como el mantenimiento del orden durante su celebración, y velar por el cumplimiento de la Ley. En cada punto del orden del día es el moderador de las intervenciones de los socios, a él le corresponde dar paso a sus intervenciones, incluso retirar la palabra o llamar la atención a alguno de los socios, decidir cuando un punto del orden del día está suficientemente debatido y se debe pasar a votación. En el cómputo de las votaciones, deberá comunicar a la Asamblea el resultado y declarar aprobada o rechazada la propuesta sometida a votación. En alguna Ley autonómica se le confiere expresamente la facultad de decidir sobre las representaciones dudosas, y cuando lo establezca la Ley o los estatutos podrá decidir sobre la asistencia de terceros no socios, salvo que lo rechace la asamblea por acuerdo mayoritario, o incluso expulsar de la reunión a los asistentes que hagan obstrucción o falten al respeto de la asamblea o a alguno de los asistentes.

La elaboración de lista de asistentes es responsabilidad del Secretario, a quien también le corresponde levantar acta de la reunión salvo que la junta se celebre en presencia de Notario, en este caso, el acta notarial será el acta de la junta.

\section{B. El quórum y lista de asistentes}

La Asamblea puede celebrarse cuando asistan socios suficientes para cubrir el quórum mínimo de asistencia fijado en la Ley y en los estatutos sociales. La LCoop. establece que en primera convocatoria tienen que estar presentes o representados más de la mitad de los socios, y en segunda un $10 \%$ de los votos sociales o 100 votos, si bien es posible que en los estatutos se fije una asistencia inferior para la segunda convocatoria. Incluso los estatutos pueden establecer que en segunda convocatoria la asamblea estará constituida cualquiera que sea el número de socios asistentes (tengase en cuenta que quórum mínimo de asistencia puede variar de unas Leyes Autonómicas a otras).

El quórum de asistencia se puede ampliar estatutariamente, pero existen algunas restricciones, por un lado no parece conveniente que en 
primera convocatoria se pueda llegar a exigir la presencia del $100 \%$ del capital social, y respecto a la segunda convocatoria, este debe ser inferior al quórum previsto para la primera, debiendo respetarse en su caso los límites máximos previstos en alguna Ley autonómica. La LCoop permite la posibilidad de introducir en los estatutos una previsión por la que se establezca en relación con el quórum de asistencia el porcentaje de asistentes que deben ser socios que desarrollen actividad cooperativizada.

El cumplimiento con la exigencia del quórum necesario para la celebración de la asamblea se refleja formalmente en la lista de asistentes. La lista de asistentes es un documento anexo al original del acta, que identifica a los socios que asisten personalmente o representados. El contenido de la lista es sencillo, una referencia a los datos de la sociedad y la asamblea, y al nombre y apellidos de los socios asistentes, y en su caso los datos de los representantes. La Ley no exige que la lista sea firmada por los socios asistentes, y en su caso por los representantes, pero si resulta conveniente para dejar constancia de la realidad. Excepcionalmente para las asambleas universales se exige que se firme el acta previa de constitución. La lista de asistentes como documento anexo al acta no tiene que transcribirse al libro de actas de la asamblea, pero debe conservarse en su caso junto con el original del acta. La lista de asistentes debe firmarse por el presidente y el secretario de la reunión.

En relación con la posible celebración de la asamblea a través de medios telemáticos se trata de una cuestión que no aparece regulada en todas las Leyes autonómicas de cooperativas, y dadas las especialidades de la celebración de una asamblea por medios telemáticos, tanto en lo que se refiere a al organización como a la propia participación del socio, entendemos que es una posibilidad reservada sólo a aquellos supuestos en que la Ley lo permita expresamente, tal y como lo admite el art. 32.1 de la Ley Catalana, para cuando se hubiera previsto en los estatutos. En este caso, también es necesario que con carácter previo a la celebración de la reunión por medios telemáticos se compruebe la relación de asistentes a efectos del quórum y de elaboración de la lista de asistentes. Por ello nos parece que en los estatutos se debe establecer como medio telemático previsto para celebrar la asamblea, un medio que permita computar las asistencias desde el memento de comienzo de la reunión, y que sirviera para dejar constancia de la participación de las socios.

\section{Sobre el desarrollo de la reunión. El derecho de voto}

La sesión se abre una vez que proclama el presidente la existencia del quórum necesario para dar comienzo a la reunión, a continuación 
la mesa irá leyendo por orden los distintos puntos del orden del día y sometiéndolos a debate y votacion. El desarrollo normal de las cosas hace que en relación con cada punto concreto del orden del día, en primer lugar tome la palabra el órgano de administración para presentar el contenido de la propuesta sometida a aprobación, y en su caso, de los documentos sometidos a aprobación, entre los que se encontrarían los correspondientes informes cuando sean preceptivos o simplemente lo considere oportuno.

Después de leerse el punto del orden del día que se va a tratar, y presentarse la propuesta sobre su contenido que se somete a aprobación, el presidente cede la palabra a los socios presentes para que hagan los comentarios que resulten oportunos, y posteriormente se somete el punto del orden del día a votación. Al presidente de la asamblea le corresponde ceder el uso de la palabra a los socios, velar por el orden de las intervenciones, y en su caso cuando sea necesario para el buen desarrollo de la reunión, puede limitar el numero de intervenciones a favor y en contra de la propuesta, así como considerar el punto suficientemente debatido y someterlo a votación. El presidente debe tratar con igualdad a todos los socios en el ejercicio de sus competencias.

El derecho al voto del socio es inderogable, y está sometido a la regla general de un socio un voto. Esta regla admite excepciones, así en las cooperativas agrarias, los estatutos pueden establecer el derecho al voto plural ponderado en proporción al volumen de actividad cooperativizada del socio, que no puede ser superior en ningún caso a cinco votos sociales, sin que pueda corresponderle a un solo socio más de un tercio de votos totales de la cooperativa. Por otro lado, en aquellos casos en que como socios de la cooperativa participen Sociedades Agrarias de Transformación, comunidades de bienes, comunidades de regantes, comunidades de aguas o sociedades civiles o mercantiles con el mismo objeto social o complementario, los estatutos pueden regular el límite de votos que ostenten estos socios en relación con el conjunto de votos sociales de la cooperativa.

No obstante lo anterior, los socios no podrán votar cuando se encuentren en situación de conflicto de intereses, porque se trata de situaciones en las que se priva al socio del ejercicio del derecho al voto ante la presencia de un conflicto entre los intereses de la cooperativa y lo que el socio pretende al margen de su interés especifico como socio. Las situaciones de conflicto de intereses aparecen determinadas en la Ley y en los estatutos de la sociedad. La LCoop. remite a los estatutos la determinación de los supuestos en los que el socio deba abstenerse de votar por encontrarse en situación de conflicto, y establece 
que como mínimo deben incluirse los previstos para las Sociedades de Responsabilidad Limitada, de manera que como mínimo el socio estará en situación de conflicto de intereses cuando se trate de adoptar un acuerdo que le excluya de la sociedad, le libere de una obligación o le conceda un derecho, o por el que la sociedad decida anticiparle fondos, concederle créditos o prestamos, prestar garantías o así como cuando siendo administrador, el acuerdo se refiera a la dispensa de la prohibición de competencia.

En función del contenido del orden del día es posible que la votación deba ser secreta (art. 25.3 LCoop). Esto ocurrirá en aquellos supuestos previstos expresamente en la Ley y en los estatutos, además de aquellos otros casos en los que así lo aprueben el 10\% de los socios presentes o representados a solicitud de cualquier socio. El propio legislador es consciente de que este último supuesto puede dar lugar a abusos que dificulten el normal funcionamiento de la asamblea, y por ese motivo, establece que los estatutos podrán regular cautelas, entre las que se puede establecer que sólo pueda promoverse una votación secreta en cada sesión cuando por el número de asistentes, la densidad del orden del día o por otra causa razonable resulte más adecuado para el desarrollo de la sesión. Los supuestos en los que tradicionalmente se establece en la Ley que es necesaria la votación secreta son los acuerdos de expulsión de socios, de elección o revocación de cargos sociales, o para aprobar el ejercicio de la acción social de responsabilidad contra los miembros de los órganos sociales, así como en los acuerdos para transigir o renunciar al ejercicio de la acción.

La Ley exige que se alcancen unas determinadas mayorías para que los acuerdos sometidos a votación puedan considerarse aprobados, y corresponde a la mesa comprobar que concurre dicha mayoría antes de manifestar si la propuesta se ha aprobado o no. La regla general es que para la aprobación de los acuerdos es necesaria la mitad más uno de los votos presentes a favor de la aprobación del acuerdo. Los votos en blanco y las abstenciones no se computan.

No obstante, cuando se trate de aprobar acuerdos que afectan a determinados supuestos especiales para la vida de la sociedad, como los de modificación de Estatutos, adhesión o baja en un grupo cooperativo, transformación de la sociedad, fusión escisión, disolución, y reactivación, la Ley exige para su aprobación una mayoría especial, y es necesario el voto favorable de dos tercios de los votos presentes y representados. En la Legislación autonómica se incluyen también en alguna Ley entre los supuestos especiales, la aprobación de los acuerdos que entrañen nuevas obligaciones o cargas gravemente onerosas para los socios no previstas en los estatutos, y el acuerdo de revocación de 
los miembros del consejo rector cuando no conste en el orden del día o el ejercicio de la acción de responsabilidad contra los mismos, y los de emisión de participaciones y títulos participativos así como la cesión o traspaso de la empresa o de alguna parte de ella que tenga la consideración de centro de trabajo, o de alguno de sus bienes, derechos o actividades que supongan modificaciones sustanciales en la estructura económica, organizativa o funcional de la cooperativa.

En los Estatutos se pueden establecer mayorías superiores a las previstas en la Ley, el límite varía de unas leyes a otras, así en la LCoop el límite consiste en que la mayoría exigida no puede rebasar las cuatro quintas partes de los votos válidamente emitidos.

\section{El acta de la reunión}

Una vez debatidos los puntos del orden del día, hay que decidir cual será el sistema de aprobación del acta, existen dos posibilidades, si se ha redactado el original del acta conforme se desarrollaba la sesión, puede aprobarse por la propia Asamblea como último punto del orden del día. En los demás casos, se debe aprobar dentro de los 15 días siguientes, para ello será necesaria la aprobación del acta por el presidente de la Asamblea, y por dos socios designados entre los asistentes por la propia Asamblea. En este caso al final del texto del acta debe constar una diligencia de aprobación en la que figure su firma. Cuando asiste un notario para levantar acta de la reunión, el acta notarial será el acta de la asamblea, no siendo necesario que se apruebe el acta.

En cuanto al contenido mínimo del acta, de acuerdo con lo dispuesto en el art. 29 de la LCoop., debe reflejar:

a) El lugar, la fecha y hora de reunión

b) Si se celebra en primera o en segunda convocatoria

c) La manifestación de la existencia de quórum suficiente

d) El orden del día

e) Resúmenes de las deliberaciones e intervenciones de las que se haya solicitado dejar constancia en acta.

f) La trascripción de los acuerdos adoptados y el resultado de las deliberaciones.

También hay que incluir una referencia a la propia convocatoria de la Asamblea, dejando constancia del cumplimiento de los anuncios previstos en la Ley y en los estatutos.

En el texto del acta se incluye una mención al número de asistentes a efectos de reflejar que concurre el quórum exigido, pero junto al 
original del acta, y como anexo debe acompañarse la lista de asistentes, en la que constarán los datos de los socios asistentes y, en su caso de los representantes. Esta lista firmada por el presidente y secretario de la sesión debe conservarse por la cooperativa, con independencia de la trascripción del contenido del acta al libro de actas de la asamblea. En relación con los documentos que sirven para acreditar la representación también deben conservarse por la Cooperativa (resulta útil la previsión que establece la Ley Valenciana en el art. 38 que deben conservarse durante el plazo previsto en la Ley para la impugnación de los acuerdos sociales).

Una vez aprobada el acta debe transcribirse al libro de actas de la Asamblea General, la LCoop no indica el plazo que tiene el secretario del Consejo, o en su caso el administrador único como responsable del libro, para transcribir el contenido del acta, pero teniendo en cuenta que se trata del cumplimiento de una obligación debe hacerse lo antes posible, a estos efectos resulta significativo que alguna Ley autonómica de Cooperativas si establece el plazo para su trascripción. Además si los acuerdos adoptados son inscribibles en el Registro de Cooperativas el órgano de administración deberá inscribirlos en el plazo de un mes. Cualquier socio interesado podrá solicitar del órgano de administración un certificado del acta, en principio si el órgano de administración está configurado por medio de un Consejo Rector, le corresponde al Secretario la capacidad de certificar, si fuera un administrador único le corresponde a este.

Los acuerdos aprobados por la asamblea producen efectos y son eficaces a partir de su aprobación. En relación con los acuerdos cuya inscripción en el Registro de Cooperativas tenga efectos constitutivos no producirán todos sus efectos hasta que la inscripción tenga lugar, pero ello no significa que dichos acuerdos no vinculen a los socios y a los administradores que deben hacer lo posible para la inscripción de los mismos en el registro.

\section{Impugnación de los acuerdos sociales}

Siguiendo el régimen previsto para la impugnación de los acuerdos de las sociedades anónimas la LCoop establece que los acuerdos de la Asamblea general son impugnables si resultan contrarios a la Ley, a los Estatutos o si perjudican los intereses sociales a favor de uno o varios socios o terceros (art. 31). Los acuerdos contrarios a la Ley son nulos, los demás acuerdos impugnables son anulables. Este régimen se sigue en la legislación cooperativa de las distintas Comunidades Autónomas si bien encontramos con diferencias que más adelante destacaremos. 
Para que un acuerdo sea nulo es necesario que lo declare una sentencia o un laudo como consecuencia de su impugnación, por eso se ha llegado a firmar que la invalidez del acuerdo queda automáticamente sanada como consecuencia del transcurso de los plazos de impugnación, que son plazos de caducidad. Excepcionalmente, para los acuerdos que sean contrarios al orden público el transcurso del tiempo no tendría efectos sanadores.

La Ley establece que no procederá la impugnación de un acuerdo que haya sido dejado sin efecto o sustituido válidamente por otro. La propia Asamblea General puede subsanar los defectos de sus acuerdos antes de su impugnación, por medio de un nuevo acuerdo adoptado en otra Asamblea. En consecuencia es necesaria una nueva Asamblea en la que se deje sin efecto el acuerdo que pueda resultar impugnable, en este caso aunque la regla general es que los acuerdos producen efectos desde su adopción, atendiendo a la naturaleza de los defectos que motivan el nuevo acuerdo, es defendible su eficacia retroactiva en tanto se trataba de un acuerdo viciado. En cuanto a la subsanación, se trata de eliminar los defectos que hacían impugnable el acuerdo, y para que ello sea posible es necesario un nuevo acuerdo con el mismo contenido que el anterior, ajustándose a la Ley y los estatutos.

El régimen previsto para su impugnación varía dependiendo de que se trate de acuerdos nulos o anulables, siendo distinto el plazo de ejercicio de la acción y la legitimación para impugnar. Si se trata de acuerdos anulables el plazo es de cuarenta días, contados a partir de la fecha de celebración de la Asamblea, o desde la fecha de su inscripción en el registro competente si se trata de acuerdos inscribibles. Si se trata de acuerdos nulos el plazo de impugnación es de un año, salvo que se trate de acuerdos contrarios al orden público, porque en ese caso el plazo de impugnación no caduca. Alguna ley autonómica establece expresamente que la interposición ante los órganos sociales de los recursos que se establecen en la Ley interrumpe los plazos para el ejercicio de las acciones de impugnación que puedan corresponder a los socios.

Respecto de la legitimación para impugnar los acuerdos nulos, está legitimado cualquier socio, los administradores, los interventores, en su caso el comité de recursos, y cualquier tercero con interés legitimo. Pero para la impugnación de los acuerdos anulables sólo están legitimados, los socios que se hubieran opuesto en acta a la aprobación del acuerdo o lo comunique fehacientemente dentro de las 48 horas siguientes, los ausentes y aquellos que hubiesen sido privados ilegítimamente de su derecho de voto. Mientras que para los socios y terceros, la impugnación de los acuerdos es un derecho, hay leyes autonómicas que establecen que para los miembros del Consejo Rector es una obli- 
gación el ejercicio de la acción de impugnación siempre que se trate de acuerdos contrarios a la Ley o a los Estatutos.

En cuanto al procedimiento previsto para la impugnación de los acuerdos sociales, La LCoop se remite a lo dispuesto en la LSA, por lo que la acción debe tramitarse según las normas del proceso ordinario, resultando competente para conocer la demanda el Juez de lo Mercantil con jurisdicción en el lugar donde la sociedad tenga su domicilio. La impugnación de los acuerdos sociales puede someterse a arbitraje, tal y como admite expresamente la Disposición Adicional Décima de la LCoop, que declara el carácter negocial y dispositivo de los acuerdos sociales, manifestando que no quedan excluidos de arbitraje las pretensiones de nulidad de impugnación de acuerdos asamblearios. Se entiende que dicha Disposición adicional, debe interpretarse conforme a la Ley de Arbitraje (Ley 60/2003, de 26 de diciembre), de manera que serán impugnables por medio de arbitraje los acuerdos sociales, cuando se haya celebrado un convenio arbitral. El convenio arbitral tiene que cumplir con lo dispuesto en el artículo 9 de la Ley de Arbitraje, por lo que debe quedar clara la voluntad de las partes de someter a arbitraje la impugnación de los acuerdos sociales.

\section{Bibliografía}

AAVV: Cooperativas. Comentarios a la Ley 27/ 1999, de 16 de julio, t. I,

Ed. Colegios Notariales de España, Madrid, 2001.

AAVV: Sociedades Mercantiles, Memento Práctico Fancis Lefebre, 2005.

Bolas Alfonso, J.: La Junta General de accionistas, Ed CISS, Madrid, 1999.

Carazo Liébana, M. J.: El arbitraje societario, Ed. Marcial Pons, Madrid, 2005.

CUENCA ANAYA, en AAVV: Comunidades de bienes, Cooperativas y otras formas de empresas, pp. 1451 y ss.

Esteban Velasco, G.: El poder de decisión en las sociedades anónimas, Ed Civitas, Madrid, 1982.

Fernandez Del Pozo/Vicent Chulia: «Internet y Derecho de sociedades. Una aproximación», $R D M, \mathrm{n} .^{\circ} 237,2000$.

GadeA, E.: Derecho de las Cooperativas. Análisis de la Ley 4/1993, de 24 de junio, de Cooperativas del Pais Vasco, Ed. Universidad de Deusto, Bilbao, 1999.

Gadea/Sacristan/Nargas: La Sociedad Cooperativa del siglo XXI, Ed Dykinson, Madrid, 2009.

GIRON Tena, J.: «Derecho de sociedades», t. I, Parte General Sociedades Colectivas y Comanditarias, 1976.

Juste Mencia, J.: «La solicitud de convocatoria de la Junta General extraordinaria por accionistas que representen el 5 por 100 del capital social», RdS, n. ${ }^{\circ} 4,1995$. 
Martínez Segovia, F.:«Sobre el concepto jurídico de cooperativa», en AAVV, La sociedad cooperativa un análisis de sus características societarias y empresariales, coord. MoyAno Fuentes, Jaen, 2001.

Morilla Jarillo/Felú ReY: Curso de Cooperativas, 2. ${ }^{a}$ Ed, Ed Técnos, 2002.

PASTOR SAMPERE, C.: «Consejo rector (Administradores) y dirección», REVESCO, núm. 77, pp. 150 y ss, 2002.

Paz Canalejo/Vicent Chuliá. F.: «Comentarios al Código de Comercio y legislación mercantil especial», t. XX, Ley General de Cooperativas, vol. 2, Ed. Edersa, 1990.

PAoluccl, L.: La societá cooperative dopo la reforma, Padova, 2004.

Paniagua ZurRera, M.: «Las sociedades Cooperativas. Las sociedades mutuasa de seguros y las mutualidades de previsión social», en Tratado de Derecho Mercantil, dir. Olivencia/Fernández Novoa/Jiménez de Parga, Ed. Marcial Pons, Madrid, 2005.

Pendas Diaz/Alonso Soto/Garcia Escudero/Prieto Gutierrez: Manual de Derecho Cooperativo, Ed Praxis, Barcelona, 1987.

SACRISTAN BERGIA, F.: "La asamblea general en el marco de las cooperativas agrarias y las sociedades agrarias de transformación», en Cooperativas Agrarias y Sociedades Agrarias de Transformación, PULGAR EzQUeRRANARGaS VASSEROT, Madrid, Dykinson, 2006, pp. 463-494.

SÁnchez RuIz, M.: "Asamblea General», La sociedad cooperativa en la Ley 27/ 1999 de 16 de julio de Cooperativas, AAVV, coord. Alonso EspinosA, Granada, 2001.

SANDUll/SANTORO: «La riforma delle societá», Societá Cooperative, Ed. Giappicheli, Torino, 2000.

SANZ JARQUe, J.: Cooperación. Teoría General y Régimen de las Sociedades Cooperativas. El nuevo derecho Cooperativo, Ed Comares, Granada, 1994.

Suso VIDAL, J.M.: "La confluencia del derecho de sociedades mercantiles en el régimen de órganos sociales de la Ley de Cooperativas de Euskadi», en VVAA, Estudios jurídicos en homenaje al Profesor Aurelio Menéndez, t. II, pp. 2537 y ss.

TATO PLAZA, A.:Sustitución y anulación por la sociedad de acuerdos sociales impugnables, Ed. McGrawHill, Madrid, 1997.

Uria/Menendez/Muñoz Planas: "La junta general de accionistas», en Comentarios Cívitas L.S.A., 1992.

VARGAS VASSEROT, C.:" «El uso de las nuevas tecnologías en las sociedades cooperativas», en Derecho Patrimonial y tecnología, coord. MADRID PARRA/GUERRERO LEBRON, Marcial Pons, Madrid, 2007.

VICENT ChULIÁ, F.: «Los órganos sociales de las cooperativas», RJC, 1978. 